\title{
PERSEPSI MASYARAKAT TERHADAP POTENSI MADU HUTAN DI DESA SEMUNTAI KECAMATAN KETUNGAU HILIR KABUPATEN SINTANG
}

\author{
(Community Perception Of Potential Forest Honey In Semuntai Village Ketungau Hilir District \\ Sintang Regency)
}

\author{
Ria Ariyani, Emi Roslinda, M. Sofwan Anwari \\ Fakultas Kehutanan Universitas Tanjungpura Jl. Daya Nasional, Pontianak 78124 \\ Email : riaariyani270@gmail.Com
}

\begin{abstract}
The Semuntai Villagers have preserved existing forest honey by not destroying the forest where honey is located, so it can be harvested several months to increase economic income for the villagers. The study of people's perceptions of the potential of forest honey in Desa Semuntai, Kecamatan Ketungau Hilir, Kabupaten Sintang, has not been carried out, so the research on the forest honey is needed. The purpose of this study was to examine people's perceptions of the potential of forest honey and examine the factors that influence the perceptions of the Semuntai villagers on the potential of forest honey. This study used a survey method with interview techniques that are assisted by questionnaires. The sampling was conducted using purposive random sampling technique. The data analysis was carried out by descriptive analysis and inferential analysis. The results showed that the people's perception of the potential of forest honey in Desa Semuntai, Kecamatan Ketungau Hilir tended to be neutral, were people who knew the potential of forest honey and felt the benefits of forest honey themselves but did not understand the purpose and function itselves. The villagers that tended to have a moderate level of knowledge do not mean they have less understanding but are based on what they see. The highest income level is the medium category, which is Rp.8,795,513.70-Rp.16,186,024.76 with 50 respondents. The level of income respondents vary due to the different sources of income for each respondent, the main job of the dominant respondents is rubber farmers and farming as a side job. People who tend to have a moderate cosmopolitan level are people who have moderate knowledge of the potential of forest honey. They obtain and seek information from television or radio to get information about the potential of forest honey.
\end{abstract}

Keywords: Community Perception, Potential Forest Honey, Semuntai

\section{PENDAHULUAN}

Berdasarkan Peraturan Menteri Kehutanan No P.35/Menhut-II/2007 telah ditetapkan jenis-jenis HHBK (hasil hutan bukan kayu) yang terdiri atas 9 kelompok HHBK yang terdiri atas 557 spesies tumbuhan dan hewan. HHBK Pada saat ini terdapat 5 jenis HHBK yang mendapat prioritas pengembangannya yaitu rotan, bambu, lebah, sutera, dan gaharu. Madu hutan merupakan salah satu jenis madu alami yang tidak mendapatkan perlakuan khusus dari manusia, sehingga membuat madu hutan sangat aman untuk dikonsumsi. Hampir semua orang menyukai madu hutan murni, akan tetapi kebanyakan dari mereka kesulitan untuk mendapatkannya. Madu hutan berpotensi untuk dikembangkan karena sumber pakan lebah yang melimpah (hampir semua tumbuhan yang 
menghasilkan bunga dapat dijadikan sebagai sumber pakan) baik yang berasal dari tanaman hutan, tanaman pertanian maupun tanaman perkebunan (Setiawan et al., 2016).

Menurut Sarlito (2010) berpendapat persepsi secara umum merupakan proses perolehan, penafsiran, pemilihan dan pengaturan informasi indrawi. Persepsi pada saat seseorang meniram stimulus dari dunia luar yang ditangkap oleh organ-organ bantunya yang kemudian masuk kedalam otak. Persepsi juga merupakan proses pencarian informasi untuk pahami yang menggunakan alat penginderaan. Penelitian ini bertujuan Mengkaji persepsi masyarakat terhadap potensi madu hutan di Desa Semuntai Kecamatan Kabupaten Sintang dan Mengkaji faktor-faktor yang mempengaruhi persepsi masyarakat Desa Semuntai terhadap potensi madu hutan dengan tingkat pengetahuan, pendapatan dan kosmopolitan.

Kajian tentang persepsi masyarakat terhadap potensi madu hutan di Desa Semuntai Kecamatan Ketungau Hilir Kabupaten Sintang belum dilakukan, sehingga perlu dilakukan penelitian tersebut. Berdasarkan uraian di atas, maka penelitian tentang bagaimana persepsi masyarakat terhadap potensi madu dan faktor apa saja yang mempengaruhi persepsi masyarakat terhadap potensi madu hutan di Desa
Semuntai Kecamatan Ketungau Hilir Kabupaten Sintang.

\section{METODE PENELITIAN}

Penelitian ini dilakukan di Kawasan hutan Desa Semuntai Kecamatan Ketungau Hilir Kabupaten Sintang. Pengumpulan data dilakukan dalam waktu 4 minggu pada tanggal 28 oktober-24 november 2018, dilakukan dengan teknik wawancara langsung menggunakan alat bantu kuisioner. Metode pengambilan sampel responden pada penelitian ini adalah dengan teknik purposive random sampling, penentuan jumlah responden menggunakan rumus Slovin (Ade, 2017) seperti berikut:

$\mathrm{n}=\frac{\mathrm{N}}{1+\mathrm{Ne}^{2}}$

Dimana:

$\mathrm{n} \quad=$ Jumlah Sampel responden

$\mathrm{N} \quad=$ Jumlah Populasi responden

$\mathrm{E} \quad=$ Persentase ketidaktelitian yang masih dapat di tolerir (10\%).

Kriteria masyarakat yang dijadikan responden secara purposive random sampling adalah (1) kepala keluarga yang berada/berdomisili di Desa Semuntai (2) sehat jasmani dan rohani (3) penduduk asli Desa Semuntai dan penduduk pendatang yang telah menetap di Desa Semuntai minimal 5 tahun. berdasarkan perhitungan rumus Slovin didapat total responden 65 kepala keluarga. Untuk lebih jelas, jumlah respoden dapat dilihat pada tabel 1 berikut. 
Tabel 1. Jumlah Populasi Dan Sampel Responden Penelitian (Total Population and Sample of Respondents Research)

\begin{tabular}{|c|c|c|c|c|}
\hline No & Lokasi/Dusun & $\begin{array}{l}\text { Jumlah } \\
\text { (KK) }\end{array}$ & Populasi & Jumlah Sampel (KK) \\
\hline 1 & Tanjung Batas & 105 & & 36 \\
\hline 2 & Sungai Putih & 84 & & 29 \\
\hline Total & & 189 & & 65 \\
\hline
\end{tabular}

Data yang dikumpulkan meliputi (1) data primer yaitu mengenai data mengenai persepsi masyarakat desa semuntai terhadap potensi madu hutan yang dihubungkan berdasarkan tingkat pengetahuan, tingkat pendapatan dan tingkat kosmopolitan, (2) Data sekunder, yaitu data-data yang diperoleh dari studi literatur maupun dari sumber yang terkait serta data penunjang lainnya yang berhubungan dengan keadaan lokasi penelitian. Analisis data dalam penelitian ini diperoleh data kualitatif ditabulasi menjadi data kuantitatif dengan menggunakan skala Likert. Skala Likert digunakan untuk mengukur sikap dan persepsi seseorang atau sekelompok tentang kejadian atau gejala sosial dengan bobot penilaian sebagai berikut (Riduwan dalam Ade, 2017). Untuk pertanyaan positif, bobot penilaian: sangat setuju (5), setuju (4), kurang setuju (3), tidak setuju (2), dan sangat tidak setuju (1).

Untuk membedakan kategori berdasarkan berdasarkan perhitungan atau rumus Standar Deviasi dengan bantuan komputer ( Microsoft Excel) dengan rumus sebagai berikut.

$S D=\frac{\sqrt{n \sum x i^{2}-\left(\sum x i^{2}\right)}}{\mathrm{n}(\mathrm{n}-1)}$

Keterangan $: \mathrm{SD}=$ Standar Deviasi

$\mathrm{n}=$ Jumlah Responden

$\mathrm{xi}=$ Nilai $\mathrm{x}$ ke 1 sampai ke $\mathrm{n}$

$\mathrm{x}=$ Nilai rata - rata
Tingkat persepsi dapat tersebut dapat dikategorikan sebagai berikut.

1. Positif, jika pendapatan masyarakat > $\mathrm{x}+\mathrm{SD}$

2. Netral, jika pendapatan masyarakat $\operatorname{antara} \mathrm{x}-\mathrm{SD} \mathrm{s} / \mathrm{d} \mathrm{x}+\mathrm{SD}$

3. Negatif, jika pendapatan $<\mathrm{x}-\mathrm{SD}$

Analisis data dilakukan secara deskriptif dan analisis inferensial. Analisis deskriptif menggunakan uji statistik deskriptif uji chi square untuk melihat tingkat persepsi masyarakat terhadap potensi madu hutan. Rumus chi square sebagai berikut:

$\mathrm{X}^{2}=\sum_{i=1}^{k} \frac{\left(\mathrm{f}_{\mathrm{o}}-\mathrm{f}_{\mathrm{h}}\right)^{2}}{\mathrm{f}_{\mathrm{n}}}$

Keterangan :

$\mathrm{X}^{2}=$ Chi Kuadrat

$\mathrm{F}_{\mathrm{o}}=$ Frekuensi di peroleh dari hasil survey

$F_{h}=$ Frekuensi yang di harapkan $(n / k)$

Analisis inferensial menggunakan uji statistik non parametrik kendall tau untuk mengetahui hubungan antara variabel terikat (persepsi masyarakat terhadap potensi madu hutan) dan variabel bebas (tingkat pengetahuan, tingkat pendapatan, dan tingkat kosmopolitan) dengan bantuan program komputer (SPSS 16.0 For Windows) dengan rumus (Sugiyono, 2010).

$\tau=\frac{\sum \mathrm{A}-\sum \mathrm{B}}{\frac{\mathrm{N}(\mathrm{N}-1)}{2}}$

Keterangan : 
$\tau=$ Koefesien korelasi kendall tau yang besarnya $(-1<0<1)$

$\mathrm{A}=$ Jumlah rangkaian atas

$\mathrm{B}=$ Jumlah Rangkaian bawah

$\mathrm{N}=$ Jumlah gagasan sampel

HASIL DAN PEMBAHASAN

Karakteristik Responden Berdasarkan

Tingkat Pengetahuan
Frekuensi tingkat pengetahuan yaitu 2 responden $(3,08 \%)$ termasuk dalam kategori tingkat pengetahuan tinggi, 57 responden (87,69\%) termasuk dalam kategori tingkat pengetahuan sedang, dan 6 responden $(9,23 \%)$ termasuk dalam kategori tingkat pengetahuan rendah. Guna ingin jelas lihat tabel 2 .

Tabel 2. Frekuensi Responden Berdasarkan Tingkat Pengetahuan(Respondent's Frequency Based on Knowledge Level)

\begin{tabular}{rccc}
\hline No & Kategori & Frekuensi (Orang) & Persentase(\%) \\
\hline 1 & Tinggi & 2 & 3,08 \\
2 & Sedang & 57 & 87,69 \\
3 & Rendah & 6 & 9,23 \\
\hline & Jumlah & $\mathbf{6 5}$ & $\mathbf{1 0 0}$ \\
\hline
\end{tabular}

Hasil pengamatan dilapangan rendah ataupun sedang bukan berarti

masyarakat yang cenderung mempunyai tingkat pengetahuan tinggi yaitu masyarakat yang mau mencari informasi tentang pontensi madu hutan, mempunyai pola pikir yang baik dan mau menerima informasi dari luar. Masyarakat yang cenderung mempunyai tingkat pengetahuan sedang bukan berarti masyarakat yang mempunyai pemahaman yang kurang tapi berdasarkan apa yang mereka lihat. Masyarakat yang mempunyai tingkat pengetahuan rendah adalah yang memiliki persepsi yang negatif tentang potensi madu hutan ini menyatakan pengetahuan seseorang berpengaruh terhadap pandangan seseorang jika pengetahuan masyarakat Tabel 3. Frekuensi Responden Berdasarkan Tingkat Pendapatan (Respondent's Frequency Based on Income Level)

\begin{tabular}{|c|c|c|c|c|}
\hline No & Pendapatan (Rp/Tahun) & Kategori & Frekuensi & Persentase (\%) \\
\hline 1 & $>16.186 .024,76$ & Tinggi & 9 & 13,85 \\
\hline 2 & $8.795 .513,70-16.186 .024,76$ & Sedang & 50 & 76,92 \\
\hline 3 & $<8.795 .513,70$ & Rendah & 6 & 9,23 \\
\hline \multicolumn{2}{|r|}{ Jumlah } & & 65 & 100 \\
\hline nas & ang cenderu & & $\begin{array}{l}\text { pendapat } \\
\text { kategori }\end{array}$ & $\begin{array}{l}\text { yang terbanyak } \\
\text { sedang } \quad \text { yaitu }\end{array}$ \\
\hline
\end{tabular}


Rp.8.795.513,70-Rp.16.186.024,76

dengan 50 responden. Variasi tingkat pendapatan responden dikarenakan oleh sumber penghasilan yang berbeda-beda setiap responden, sumber mata pencaharian utama responden yang dominan adalah petani karet dan mata pencaharian sampingan adalah berladang. Petani karet dengan pendapatan rata-rata sebesar Rp10.000.000/tahun dan berladang pendapatan masyarakat Desa Semuntai rata-rata Rp5.500.000/tahun.
Karakteristik

Berdasarkan Kosmopolitan

Frekuensi tingkat kosmopolitan responden di Desa Semuntai memiliki kategori tinggi 18 responden $(27,69 \%)$ termasuk dalam tingkat kosmopolitan kategori tinggi, 24 responden $(36,92 \%)$ termasuk dalam tingkat kosmopolitan kategori sedang, dan 23 responden $(35,38 \%)$ termasuk dalam tingkat kosmopolitan kategori rendah.

Tabel 4. Frekuensi Responden Berdasarkan Tingkat Kosmopolitan (Frequency of Respondents Based On Cosmopolitan Level)

\begin{tabular}{cccc}
\hline No & Kategori & Frekuensi (Orang) & Persentase (\%) \\
\hline 1 & Tinggi & 18 & 27,69 \\
2 & Sedang & 24 & 36,92 \\
3 & Rendah & 23 & 35,38 \\
\hline & Jumlah & $\mathbf{6 5}$ & $\mathbf{1 0 0}$ \\
\hline
\end{tabular}

Hasil pengamatan dilapangan

masyarakat yang cenderung memiliki tingkat kosmopolitan sedang 24 responden (36,92\%) diperoleh kelompok kosmopolitan yang terbanyak. Masyarakat yang cenderung mempunyai tingkat kosmopolitan sedang adalah masyarakat yang memiliki pengetahuan sedang terhadap potensi madu hutan mereka memperoleh dan mencari informasi dari televisi atau radio untuk mendapatkan informasi tentang potensi madu hutan dengan salah satunya bagaimana menjaga kelestarian madu hutan yang jarak pohon madu hutan jauh dari rumah masyarakat.

\section{Analisis Deskriptif}

Persepsi Masyarakat Terhadap Potensi Madu Hutan Desa Semuntai

Persepsi masyarakat adalah penilaian atau respon masyarakat terhadap potensi madu hutan di Desa Semuntai. Persepsi masyarakat terhadap potensi madu hutan di Desa Semuntai dikelompokkan menjadi tiga kategori yaitu positif, netral dan negatif. Persepsi masyarakat terhadap potensi madu hutan dianalisis dengan analisis deskriptif dengan uji statistik deskriptif chi square. Frekuensi persepsi masyarakat terhadap potensi madu hutan di Desa Semuntai yang disajikan pada tabel 5 berikut ini. 
Tabel 5. Frekuensi Persepsi Masyarakat Terhadap Potensi Madu Hutan di Desa Semuntai(Frequency of Community Perception of Potential Forest Honey in Semuntai Village)

\begin{tabular}{|c|c|c|c|}
\hline No & Kategori & Frekuensi (Orang) & Persentase $(\%)$ \\
\hline 1 & Positif & 6 & 9,23 \\
\hline 2 & Netral & 41 & 63,08 \\
\hline 3 & Negatif & 18 & 27,69 \\
\hline & Jumlah & 65 & 100 \\
\hline
\end{tabular}

Nilai $\mathrm{X}^{2}$ hitung $>$ dari nilai $\mathrm{X}^{2}$ tabel (0,05), berdasarkan hasil uji analisis deskriptif disimpulkan bahwa terdapat perbedaan signifikan frekuensi persepsi masyarakat terhadap potensi madu hutan dan persepsi masyarakat cenderung netral. Berarti hipotesis yang menyatakan bahwa 41 responden $(63,08 \%)$ masyarakat Desa Semuntai Kecamatan Ketungau Hilir Kabupaten Sintang cenderung memiliki persepsi yang netral. Hasil olahan data primer sebagiamana diuraikan pada tabel 5 dan hasil uji statistik deskriptif dapat di interpretasikan bahwa dari dari 65 responden penelitian sebagian 41 responden $(63,08 \%)$ cenderung persepsi netral terhadap potensi madu hutan di Desa Semuntai. Mengacu pada hasil interpretasi maka kondisi tersebut menunjukkan bahwa sebagian besar 41 responden $(63,08 \%)$ masyarakat Desa Semuntai Kecamatan Ketungau Hilir Kabupaten Sintang cenderung netral.

Masyarakat yang cenderung mempunyai persepsi positif adalah masyarakat yang telah mengetahui manfaat dan fungsi madu hutan bagi kesehatan meningkatkan energi, memperlancar fungsi otak, kekebalan tubuh,anti tumor dan mencegah kanker, memperbaiki sistem pencernaan, dan menurunkan berat badan (Sakri, 2015) dalam kehidupan sehari-hari maka masyarakat Desa Semuntai harus menjaga kelestarian madu hutan. Masyarakat yang mempunyai persepsi cenderung netral adalah responden yang mengetahui tentang potensi madu hutan dan merasakan manfaat madu hutan itu sendiri. Tetapi tidak sepenuhnya memahami adanya tujuan dan fungsi adanya potensi madu hutan. Namun hal ini berdampak baik karena bisa menambah ekonomi masyarakat Desa Semuntai. Masyarakat yang mempunyai persepsi cenderung negatif adalah responden yang kurangnya informasi dan pengetahuan masyarakat terhadap potensi madu hutan baik dari fungsi maupun dari manfaat potensi madu hutan. Selain itu masyarakat yang mempunyai persepsi cenderung negatif disebabkan terpengaruh oleh pihak lain dari luar yang sudah mengetahui fungsi dan manfaat potensi madu hutan.

\section{Analisis inferensial}

Guna menganalisis hubungan variabel terikat dan variabel bebas di lakukan dengan Uji Statistik Non Parametrik Uji Korelasi Kendall Tau. Hasil uji korelasi Kendall Tau variabel terikat dan variabel bebas disajikan pada tabel 6 sebagai berikut: 
Tabel 6. Hasil Uji Korelasi Kendall Tau Hubungan antara Variabel Terikat dan Variabel Bebas (Kendall Tau Correlation Test Results Relationship between Bound Variables and Free Variables)

\begin{tabular}{cccccc}
\hline No & Variabel & N & $\begin{array}{c}\text { Correlation } \\
\text { coefficient }\end{array}$ & $\begin{array}{c}\text { Sig (2- } \\
\text { Tailed) }\end{array}$ & Keterangan \\
\hline 1 & Pengetahuan & 65 & 0,105 & 0,275 & Tidak Signifikan \\
2 & Pendapatan & 65 & 0,086 & 0,367 & Tidak Signifikan \\
3 & Kosmopolitan & 65 & 0,076 & 0,432 & Tidak Signifikan \\
\hline
\end{tabular}

1. Hubungan Tingkat Pengetahuan dengan Persepsi Masyarakat Terhadap Potensi Madu Hutan

Nilai sig $0,275>0,05$, dan nilai koefisien korellasi sebesar 0,105 disimpulkan bahwa terdapat hubungan tidak signifikan antara variabel tingkat pengetahuan dan tingkat persepsi terhadap potensi madu hutan di Desa Semuntai Kecamatan Ketungau Hilir Kabupaten Sintang. Hal ini berarti semakin tinggi tingkat pengetahuan masyarakat terhadap potensi madu hutan di Desa Semuntai Kecamatan Ketungau Hilir Kabupaten Sintang juga semakin positif. Berdasarkan hasil pengamatan diketahui bahwa tingkat pengetahuan masyarakat terhadap potensi madu hutan sebagian sebesar $(87,69 \%)$ tergolong dalam kategori sedang, sedangkan persepsi masyarakat terhadap potensi madu hutan sebagian sebesar $(63,08 \%)$ termasuk dalam kategori netral.

Menurut Afwatunnati pengetahuan itu sendiri dipengaruhi oleh pendidikan formal. Pengetahuan sangat erat hubungannya dengan pendidikan, dimana diharapkan bahwa dengan pendidikan yang tinggi maka orang tersebut akan semakin luas pula pengetahuannya. Akan tetapi perlu ditekankan, bukan berarti seseorang yang berpendidikan rendah mutlak berpengetahuan rendah pula. Hal ini

mengingat bahwa peningkatan
pengetahuan tidak mutlak diperoleh dari pendidikan formal saja, akan tetapi dapat diperoleh melalui pendidikan nonformal. Pendidikan dapat di peroleh dari pendidikan non formal dan keterbukaan masyarakat desa semuntai dalam mencari dan menerima informasi baru. Responden yang mempunyai tingkat pengetahuan yang tinggi yang memiliki persepsi positif adalah masyarakat yang mempunyai wawasan luas dan mau menerima informasi dari luar mengenai potensi madu hutan.

Responden dengan tingkat pengetahuan sedang cenderung mempunyai persepsi yang netral terhadap potensi madu hutan. Masyarakat yang mempunyai persepsi netral yang mempunyai pemahaman tentang potensi madu hutan berdasarkan pengetahuan dan berdasarkan pengalaman yang masyarakat miliki tentang potensi madu hutan.

\section{Hubungan Tingkat Pendapatan dengan Persepsi Masyarakat Terhadap Potensi Madu Hutan}

Berdasarkan hasil uji statistik (Uji Korelasi Kendall Tau) antara tingkat pendapatan dengan persepsi di ketahui nilai sig (2-tailed) sebesar 0,367 dan nilai correlation coefficient 0,086 . Nilai sig $0,367>0,05$ disimpulkan bahwa terdapat 
hubungan tidak signifikan antara variabel tingkat pendapatan dengan persepsi masyarakat terhadap potensi madu hutan di Desa Semuntai Kecamatan Ketungau Hilir Kabupaten Sintang. Hal ini berarti semakin tinggi tingkat pendapatan masyarakat terhadap potensi madu hutan maka persepsi masyarakat terhadap potensi madu hutan di Desa Semuntai Kecamatan Ketungau Hilir Kabupaten Sintang semakin positif.

Berdasarkan hasil pengamatan diketahui tingkat pendapatan masyarakat sebagian besar $(76,92 \%)$ tergolong dalam kategori sedang. Sehingga dapat disimpulkan bahwa pendapatan masyarakat tidak terlalu berpengaruh terhadap persepsi masyarakat terhadap potensi madu hutan. karena pendapatan masyarakat Desa Semuntai bukan berasal dari potensi madu hutan tetapi pendapatan masyarakat pada umumnya lebih besar pada pertanian dan perkebunan. Masyarakat yang mempunyai persepsi netral adalah disebabkan fungsi dan manfaat madu hutan, secara tidak langsung potensi madu hutan memberikan dampak baik bagi masyarakat sekitar Desa Semuntai. Menurut Ali (2015) tanaman karet di Indonesia merupakan salah satu komoditi perkebunan yang mempunyai peranan penting, baik ditinjau dari segi sosial maupun ekonomi. Hal ini disebabkan karena disamping penyebaran dan pengusahaannya yang cukup luas dan tersebar diberbagai wilayah Indonesia serta banyak melibatkan tenaga kerja yang dibutuhkan pada berbagai tahap pengelolaan atau kegiatannya.
Berdasarkan data di atas adalah pendapatan masyarakat Desa Semuntai cenderung sedang, karena pendapatan masyarakat Desa Semuntai hanya dari hasil bertani dan berkebun dengan rata-rata pendapatan Rp.833.333 perbulan. Karena masih banyaknya pendapatan yang masyarakat peroleh bukan dari hasil madu hutan maka tingkat pendapatan tidak berhubungan signifikan dengan persepsi. Tingkat pekerjaan berpengaruh terhadap tingkat pendapatan masyarakat Desa Semuntai Kecamatan Ketungau Hilir Kabupaten Sintang.

\section{Hubungan Tingkat Kosmopolitan Dengan Persepsi Masyarakat Terhadap Potensi Madu Hutan}

Berdasarkan hasil uji statistik (Uji Korelasi Kendall Tau) antara tingkat kosmopolitan dengan persepsi diketahui nilai sig (2-tailed) sebesar 0,432 dan nilai correlation coefficient 0,076 . Nilai sig 0,432>0,05 menunjukkan bahwa terdapat hubungan tidak signifikan antara tingkat kosmopolitan dengan tingkat persepsi masyarakat terhadap potensi madu hutan di Desa Semuntai Kecamatan Ketungau Hilir Kabupaten Sintang. Berdasarkan hasil pengamatan diketahui hasil pengamatan tingkat kosmopolitan sebagian besar $(36,92)$ tergolong dalam kategori sedang, sedangkan persepsi masyarakat terhadap potensi madu hutan sebagian besar $(63,08 \%)$ cenderung netral. Nilai korelasi menunjukkan bahwa semakin positif atau tinggi tingkat kosmopolitan masyarakat terhadap potensi madu hutan maka persepsi masyarakat terhadap potensi madu hutan akan cenderung netral atau setuju 


\begin{abstract}
Terjadinya perbedaan tingkat kosmopolitan dikarenakan adanya perbedaan penerimaan informasi yang diperoleh oleh responden. Masyarakat yang mempunyai tingkat kosmopolitan yang tinggi berarti mempunyai wawasan berfikir yang luas sehingga mampu menerima hal-hal yang sifatnya positif, sedangkan masyarakat yang mempunyai tingkat kosmopolitan yang rendah adalah masyarakat yang sulit atau tidak mau menerima hal-hal yang baru dan kurang memiliki keterbukaan dalam menerima informasi dari luar mengenai persepsi masyarakat terhadap potensi madu hutan.
\end{abstract}

Hasil penelitian Adalina (2018) menyatakan bahwa Apis dorsata merupakan salah satu jenis lebah madu yang sebaran aslinya mencakup sebagian besar wilayah Indonesia dan di kenal memiliki tingkat produktivitas tinggi. Apis dorsata tergolong lebah liar yang belum dapat dibudidayakan sehingga pemanenan hanya dilakukan melalui aktivitas pemburuan dikawasan hutan. Selain Apis dorsata, di kawasan hutan dengan tujuan khusus (KHDTK) rantau terdapat jenis lebah lainnya yaitu beberapa jenis kelulut (stingless bees) dan apis cerana. Keberadaan berbagai jenis lebah dikawasan ini ditunjang oleh tersedianya berbagai jenis tumbuhan berbunga yang menjadi sumber pakan lebah madu. Beberapa komunitas masyarakat sekitar hutan biasa menyebut pohon yang dihuni sarang lebah hutan sebagai pohon sialang.

\section{Kesimpulan}

1. Persepsi masyarakat Desa Semuntai terhadap potensi madu hutan cenderung berbeda dari 65 responden terdapat 6 responden $\quad(9,23 \%) \quad$ cenderung mempunyai persepsi yang positif, 41 responden $\quad(63,08) \quad$ cenderung mempunyai persepsi yang netral dan 18 responden $\quad(27,69 \%) \quad$ cenderung mempunyai persepsi negatif terhadap potensi madu hutan di Desa Semuntai Kecamatan Ketungau Hilir Kabupaten Sintang.

2. Terdapat hubungan yang tidak signifikan antara tingkat pengetahuan, tingkat kosmopolitan dan tingkat pendapatan dengan persepsi masyarakat terhadap potensi madu hutan di Desa Semuntai Kecamatan Ketungau Hilir Kabupaten Sintang

\section{Saran}

Adanya persepsi netral dari masyarakat Desa Semuntai terhadap potensi madu hutan, maka masyarakat diharapkan dapat mengupayakan kelestarian potensi madu hutan sehingga secara langsung maupun tidak langsung akan meningkatkan perhatian dan minat masyarakat terhadap keberadaan potensi madu hutan.

\section{DAFTAR PUSTAKA}

Adalina Y. 2018. Analisis Habitat Koloni Lebah Hutan Apis Dorsata Dan Kualitas Madu Yang Dihasilkan Dari Kawasan Hutan Dengan Tujuan Khusus (KHDTK) Rantau, Kalimantan Selatan. Jurnal penelitian hutan dan konservasi alam. 15 (1): 25-40.

Afwatunnati, Sunarko, Dan Wahyu S. 2016. Pengaruh Pengetahuan Terhadap Sikap Ibu Rumah Tangga Dalam Upaya Mengatasi Pencemaran Lingkungan Akibat Sampah Di TPA Jatibarang. Edu Geography. 4 (1) : 2252-6684. 
Ali J, Arman D, Dan Siti H. 2015. Analisis Produksi Dan Pendapatan Petani Karet Di Kabupaten Bungo. Jurnal Perspektif Pembiayaan Dan Pembangunan Daerah. 2 (4) : 2338-4603.

Peraturan Menteri Kehutanan Nomor P.35/Menhut-II/2007 Tentang Hasil Hutan Bukan Kayu. Diakses 24 April 2018

Sakri, F.M. 2015. Madu Dan Khasiatnya Suplemen Sehat Tanpa Efek Samping. Diandra Pustaka Indonesia. Yogyakarta.

Sarlito W Sarwono. 2010. Pengantar Psikologi Umum. Rajawali Pers: Jakarta
Setiawan A, Rudianda S, dan Tuti A. 2016. Strategi Pengembangan Usaha Lebah Madu kelompok Tani Setia Jaya Di Desa Rambah Jaya Kecamatan Bangun Purba Kabupaten Rokan Hulu. Jom Faperta. 3 (1) : 1 - 6.

Sugiyono. 2010. Statistik Non Parametrik Untuk Penelitian.Alfabeta. Jakarta

Wahyuningsih A. 2017 Persepsi Masyarakat Desa Pisak Terhadap Pengelolaan Model Desa Konservasi. Fakultas Kehutanan Universitas Tanjungpura. Pontianak Jurnal Hutan Lestari. 5 (4) : 898 907. 